\title{
A leucine-supplemented diet improved protein content of skeletal muscle in young tumor-bearing rats
}

M.C.C. Gomes-Marcondes ${ }^{1}$, G. Ventrucci ${ }^{1}$, M.T. Toledo ${ }^{1}$, L. Cury ${ }^{1}$ and J.C. Cooper ${ }^{2}$
${ }^{1}$ Laboratório de Nutrição e Câncer, Departamento de Fisiologia e Biofísica, Instituto de Biologia, Universidade Estadual de Campinas, Campinas, SP, Brasil ${ }^{2}$ Laboratory of Lymphocyte Signalling and Development, The Babraham Institute, Babraham, Cambridge, UK

\section{Correspondence}

M.C.C. Gomes-Marcondes

Departamento de Fisiologia e

Biofísica, Instituto de Biologia UNICAMP

13083-970 Campinas, SP

Brasil

Fax: +55-19-3788-6185

E-mail: cintgoma@unicamp.br

Research supported by FAPESP (Nos. 2001/02135-3 and 1996/9463-6), CNPq (No. 521048/95-8) and FAEP-UNICAMP (Nos. 017/2001 and 0478/2002).

Received February 18, 2003

Accepted July 15, 2003

\begin{abstract}
Cancer cachexia induces host protein wastage but the mechanisms are poorly understood. Branched-chain amino acids play a regulatory role in the modulation of both protein synthesis and degradation in host tissues. Leucine, an important amino acid in skeletal muscle, is higher oxidized in tumor-bearing animals. A leucine-supplemented diet was used to analyze the effects of Walker 256 tumor growth on body composition in young weanling Wistar rats divided into two main dietary groups: normal diet (N, 18\% protein) and leucine-rich diet (L, $15 \%$ protein plus $3 \%$ leucine), which were further subdivided into control ( $\mathrm{N}$ or $\mathrm{L}$ ) or tumor-bearing (W or LW) subgroups. After 12 days, the animals were sacrificed and their carcass analyzed. The tumor-bearing groups showed a decrease in body weight and fat content. Lean carcass mass was lower in the $\mathrm{W}$ and LW groups $(\mathrm{W}=$ $19.9 \pm 0.6, \mathrm{LW}=23.1 \pm 1.0 \mathrm{~g} v s \mathrm{~N}=29.4 \pm 1.3, \mathrm{~L}=28.1 \pm 1.9 \mathrm{~g}, \mathrm{P}<$ 0.05). Tumor weight was similar in both tumor-bearing groups fed either diet. Western blot analysis showed that myosin protein content in gastrocnemius muscle was reduced in tumor-bearing animals $(\mathrm{W}=$ $0.234 \pm 0.033 v s \mathrm{LW}=0.598 \pm 0.036, \mathrm{~N}=0.623 \pm 0.062, \mathrm{~L}=0.697$ \pm 0.065 arbitrary intensity, $\mathrm{P}<0.05)$. Despite accelerated tumor growth, LW animals exhibited a smaller reduction in lean carcass mass and muscle myosin maintenance, suggesting that excess leucine in the diet could counteract, at least in part, the high host protein wasting in weanling tumor-bearing rats.
\end{abstract}

Cachexia is a poorly understood syndrome characterized by anorexia, generalized host wasting, and a variety of metabolic alterations, which can result in death (1). The decrease in lean body mass is probably due to a reduction in protein synthesis and/or an increase in catabolism. Many studies have demonstrated that the tumor acts as a nitrogen trap, especially for amino acids, and
Key words

- Leucine

- Amino acid

- Walker 256 carcinosarcoma

- Body composition

- Skeletal muscle protein competes with the host for amino acids and glucose to satisfy its requirements (1-3). Amino acids, especially branched-chain amino acids (BCAA), play a regulatory role in modulating both protein synthesis and degradation in a wide range of tissues. Experimental evidence indicates that a major proportion of the increase in skeletal muscle protein synthesis observed in vivo following 
refeeding after a brief starvation is independent of changes in anabolic hormones (insulin) but is attributable to amino acids themselves $(4,5)$. Louard et al. (6) showed that different proportions of dietary BCAA had important beneficial effects on the metabolic changes associated with muscle wasting.

If the progression of muscle wasting seen in malignant neoplastic disease could be prevented, it would be of clinical importance in terms of improving the prognosis and the quality of life of the patients. The main objective of the present study was to investigate the effects of Walker 256 carcinosarcoma growth on the body composition of young rats, which were fed normal (AING93) and high leucine level diets (3\% leucine added to AIN-G93).

Weanling male Wistar rats (25 days old, $\mathrm{N}=36$, from the animal facilities of UNICAMP, CEMIB) were housed in metabolic cages and kept under normal conditions $\left(22 \pm 2^{\circ} \mathrm{C}\right.$, and $12 / 12$-h light/dark cycle) with free access to water and food over a 12day period. The rats were divided into four groups according to diet and tumor implantation: control $(\mathrm{N})$ and tumor-bearing $(\mathrm{W})$, which were fed an $18 \%$ protein diet, and two other groups fed a high leucine diet: nontumor-bearing (L) and tumor-bearing (LW). The semipurified control diet was AIN-G93 (7) and the high leucine diet contained 15\% protein supplemented with 3\% leucine. Each diet contained equivalent amounts of carbohydrate, fat and fiber. The tumor-bearing group was inoculated $s c$ into the right flank with $0.2 \mathrm{ml}\left(2.5 \times 10^{5}\right)$ of viable (Trypan blue exclusion) Walker 256 carcinosarcoma cells. The non-tumor-bearing rats were injected $s c$ with $0.2 \mathrm{ml} 0.9 \%$ (w/v) $\mathrm{NaCl}$ solution without anesthesia. General UKCCR guidelines (1988, United Kingdom Coordinating Committee on Cancer Research) for animal welfare were followed (Ethics Committee for Animal Research CEE and COBEA, Brazil numbered 0386-1).
Food intake, body weight, and tumor weight (calculated from three orthogonal linear measurements using the weight dimension curve; 8) were measured every two days. After 12 days the animals were killed with a Nembutal overdose followed by cervical dislocation. Gastrocnemius muscle samples were weighed and homogenized in a buffer containing $20 \mathrm{mM}$ Tris $\mathrm{HCl}, \mathrm{pH} 7.5$, $2 \mathrm{mM}$ ATP, $5 \mathrm{mM} \mathrm{MgCl}_{2}$ and $1 \mathrm{mM}$ dithiothreitol (1:4 dilution). The whole muscle homogenate was then centrifuged for $10 \mathrm{~min}$ at $9000 \mathrm{~g}, 4^{\circ} \mathrm{C}$, and the resulting supernatant was used to determine the total protein content. Samples of muscle protein $(5 \mu \mathrm{g})$ were resolved on a $12 \%$ sodium dodecyl sulfate polyacrylamide gel, transferred to a $0.45-\mu \mathrm{m}$ nitrocellulose membrane (Hybond-C, Amersham Pharmacia Biotech, Little Chalfont, Buckinghamshire, UK) and blocked with 5\% Marvel in phosphate-buffered saline containing $0.1 \%$ Tween, $\mathrm{pH} 7.5$, to quantify myosin heavy chain using a specific myosin heavy chain primary antibody, 1:250 dilution (Novocastra, Newcastle, UK).

Nitrocellulose membranes were developed using ECL chemiluminescence (Amersham) and blots quantified using a densitometer. A parallel gel was silver stained to ensure equal loading. The densitometric results were analyzed using Gel Pro Analyzer software (Media Cybernetics, Silver Spring, MD, USA). Body water content was calculated from the total body mass minus tumor mass and gastrointestinal tract (stomach to large intestine) of each rat carcass by drying and weighing until a constant weight was achieved. Carcasses were then cut into pieces for soxhlet extraction of body fat. The lean carcass mass was calculated by subtracting dry carcass without fat from dry carcass including fat. The determination of chemical whole body composition followed the methodology of Ventrucci et al. (9). Results are reported as mean \pm SEM and were analyzed with the Graph Pad Prism program, v3.00 for Windows 98. Differences were considered 
significant at $\mathrm{P}<0.05$.

Data were analyzed statistically by twoway ANOVA, testing the effects of diet and tumor on body chemical composition and muscle myosin content. Comparisons within control and tumor-bearing groups were performed using one-way ANOVA followed by post hoc Bonferroni's multiple comparison test (10).

The effects of a high leucine diet on tumor growth and body composition were examined. As shown in Table 1, the initial food intake was similar among the four experimental groups $(\mathrm{P}>0.05)$, although at the end of the experiment both tumor-bearing groups (W and LW) demonstrated a reduction in food intake when compared to nontumor-bearing rats $(\mathrm{W} v s \mathrm{~N}, \mathrm{P}<0.01 ; \mathrm{LW} v s$ $\mathrm{L}, \mathrm{P}<0.001$; Table 1). The final body weight values were lower in both tumor-bearing groups (W $v s \mathrm{~N}$ and $\mathrm{LW} v s \mathrm{~L}, \mathrm{P}<0.001$ ). The final body weight was reduced by $36.4 \%$ in group $\mathrm{W}$, differing significantly from the control group $(\mathrm{P}<0.001)$, although this difference was lower than the LW body weight value $(22.5 \%$, $\mathrm{LW}$ vs $\mathrm{L}, \mathrm{P}<0.01)$. The tumor-bearing groups showed similar final body weight $(\mathrm{LW}=117.4 \pm 2.6 v s \mathrm{~W}=96.8$ $\pm 5.1 \mathrm{~g}, \mathrm{P}>0.05)$ and tumor weight $(\mathrm{W}=$ $7.84 \pm 1.04$ and $\mathrm{LW}=7.38 \pm 0.62 \mathrm{~g}$ ). The body water content was increased in tumorbearing rats $(\mathrm{P}<0.001$ for group $\mathrm{W}$ and $\mathrm{P}<$ 0.05 for group LW). The total percentage of fat was reduced in $\mathrm{W}(\mathrm{P}<0.01)$ and in $\mathrm{LW}$ rats $(\mathrm{P}<0.001)$ compared to the respective control groups (Table 1). Lean body mass was decreased in the $\mathrm{W}$ group (W vs $\mathrm{N}$ and $\mathrm{L}$, $\mathrm{P}<0.01$, Table 1), but this decrease was less prominent in the LW group ( $\mathrm{LW} v s \mathrm{~N}, \mathrm{P}<$ 0.05; there was no difference between LW and $\mathrm{L}, \mathrm{P}>0.05$ ) in relation to the $\mathrm{L}$ group. The LW group also showed a higher lean carcass mass in comparison to the $\mathrm{W}$ group (LW vs $\mathrm{W}, \mathrm{P}<0.05$ ).

This parameter was especially affected by tumor growth when analyzed by two-way ANOVA, which showed a $\mathrm{P}$ value equal to 0.0047 . The weight of the gastrocnemius muscle (Table 1) was decreased in the $\mathrm{W}$ tumor-bearing group $(\mathrm{W}=0.152 \pm 0.016 \mathrm{~g}$, $\mathrm{P}<0.05$ for $\mathrm{W} v s \mathrm{~N}$ ), but the LW group showed only a slight reduction in muscle weight $(\mathrm{LW}=0.248 \pm 0.033 \mathrm{~g})$. A significant difference was observed when compared to

Table 1. Effects of leucine-supplemented diets on the characteristics of tumor-bearing groups.

\begin{tabular}{|c|c|c|c|c|}
\hline & $\mathrm{N}$ & L & W & LW \\
\hline Food intake on the 1 st day (g) & $7.89 \pm 0.99^{a}$ & $7.98 \pm 0.77^{a}$ & $8.63 \pm 0.45^{a}$ & $10.36 \pm 0.60^{a}$ \\
\hline Food intake on the 12th day (g) & $15.33 \pm 0.84^{a}$ & $15.86 \pm 0.78^{a}$ & $10.33 \pm 0.58^{b}$ & $9.18 \pm 0.98^{b}$ \\
\hline Body weight on the 1st day (g) & $67.7 \pm 2.4^{a}$ & $69.2 \pm 2.5^{a}$ & $64.7 \pm 2.4^{a}$ & $67.0 \pm 1.6^{\mathrm{a}}$ \\
\hline Body weight on the 12 th day $(\mathrm{g})$ & $152.3 \pm 3.9^{a}$ & $151.5 \pm 5.2^{a}$ & $96.8 \pm 5.1^{b}$ & $117.4 \pm 2.6^{b}$ \\
\hline Body weight gain $(\%)$ & $205.5 \pm 6.2^{a}$ & $197.9 \pm 6.4^{a}$ & $158.1 \pm 4.3^{b}$ & $168.0 \pm 4.3^{b}$ \\
\hline Tumor weight (g) & - & - & $7.84 \pm 1.04^{a}$ & $7.38 \pm 0.62^{a}$ \\
\hline Tumor weight/body weight ratio (\%) & - & - & $8.29 \pm 1.01^{a}$ & $6.90 \pm 0.58^{a}$ \\
\hline Body water $(\%)$ & $64.1 \pm 0.5^{\mathrm{a}}$ & $64.4 \pm 0.5^{a}$ & $70.4 \pm 0.9 b$ & $68.4 \pm 1.3^{b}$ \\
\hline Body fat (\%) & $10.7 \pm 0.4^{\mathrm{a}}$ & $13.7 \pm 0.6^{b}$ & $6.2 \pm 0.4^{c}$ & $7.9 \pm 0.9 c$ \\
\hline Lean carcass mass (g) & $29.4 \pm 1.3^{a}$ & $28.1 \pm 1.9^{a}$ & $19.9 \pm 0.6^{b}$ & $23.1 \pm 1.0^{a, b}$ \\
\hline Total protein carcass (mg/g) & $47.94 \pm 1.51^{\mathrm{a}}$ & $46.71 \pm 3.05^{a, b}$ & $42.72 \pm 1.14^{b}$ & $43.47 \pm 1.05^{b}$ \\
\hline Gastrocnemius muscle weight (g) & $0.289 \pm 0.025^{a, b}$ & $0.347 \pm 0.025^{b}$ & $0.152 \pm 0.016^{c}$ & $0.248 \pm 0.033^{a}$ \\
\hline Gastrocnemius muscle total protein $(\mu \mathrm{g} / \mu \mathrm{l})$ & $4.89 \pm 0.34^{a}$ & $5.03 \pm 0.26^{a}$ & $5.49 \pm 0.31^{a}$ & $5.82 \pm 0.20^{a}$ \\
\hline
\end{tabular}

Groups: control (N); control fed a leucine-supplemented diet (L); bearing a Walker 256 carcinosarcoma (W); tumor-bearing rats receiving a leucinesupplemented diet (LW). Data are reported as means \pm SEM for 8 animals in the $N$ and L groups and 10 animals in the W and LW groups. Significant differences are shown in each row by different superscript letters ( $P<0.05$, one-way ANOVA followed by Bonferroni's test). 
the $\mathrm{L}$ and $\mathrm{W}$ groups $(\mathrm{P}<0.05)$.

After equal protein loading ( $5 \mu \mathrm{g}$ per well), Western blot analysis showed a decrease in myosin content in the $\mathrm{W}$ tumorbearing group $(\mathrm{P}<0.001)$ (Figure 1$)$ but there was also a small reduction in myosin content in the LW group. However, myosin content was significantly higher in the LW group $(0.598 \pm 0.036)$ compared to the $\mathrm{W}$ group $(0.234 \pm 0.033, \mathrm{P}<0.001)$. Two-way ANOVA showed that the effects of diet and tumor were extremely significant, with $\mathrm{P}$ values of $<0.0001$ and 0.0008 , respectively.

The weight loss observed in patients and animals with solid tumors is primarily the result of a loss of both muscle mass and body fat $(1,11)$. Although weight loss is commonly associated with a decrease in food intake, anorexia does not appear to be responsible for the cachectic process. Depletion of host fat stores is a common characteristic of Walker 256 tumor-bearing rats, which was also observed in the present study and has been observed in other experimental tumor-bearing models involving severe weight loss $(9,12)$. In an extensive review, Tisdale (1) reported that the loss of body fat

Figure 1. A, Analysis of myosin heavy chain content in gastrocnemius muscle of control (N), Walker 256 carcinosarcomabearing rats $(\mathrm{W})$, control rats fed a leucine-supplemented diet (L), and tumor-bearing rats receiving a leucine-supplemented diet (LW). The blot is representative of 8 muscle samples from each group. Homogenized fractions from whole gastrocnemius muscle protein $(5 \mu \mathrm{g})$ were probed with a monoclonal antibody against myosin heavy chain as described in Methods. $B$, Densitometric analysis of myosin heavy chain content in gastrocnemius muscle from four separate blots (means \pm SEM for 8 animals in each group). ${ }^{*} \mathrm{P}<$ 0.001 for the $\mathrm{N}$ group compared to the $W$ group; ${ }^{*} P<0.001$ for the $W$ group compared to the LW group (two-way ANOVA). was related, in part, to an increase in glycerol and fatty-acid turnover, leading to increased lipolysis and to a circulatory lipid-mobilizing factor found in both animal and human cachectic hosts. Body fat was especially reduced in both tumor-bearing groups.

From our results, it was evident that body water content was higher in tumor-bearing rats. Other studies have also demonstrated a similar alteration in body water content in pregnant tumor-bearing rats (9) and in tumor-bearing male rats (12). Besides the profound decrease in body fat, Walker 256 carcinosarcoma-bearing rats showed a significant decrease of about $15 \%$ in lean tissue mass in comparison to control groups $(9,12)$. In contrast, studies on interleukin-6-secreting tumor-bearing mice demonstrated a significant loss in fat tissue without loss of lean body mass or water content (13). Lean body mass and visceral protein depletion is a characteristic of patients with cancer cachexia and the degree of depletion may be associated with reduced survival. According to Cohn and colleagues (11), the non-muscle tissue including the visceral fraction did not change in cancer patients, and appeared to increase in size when compared to the normal population. Although the carcass weight loss occurred in both the W and LW groups, it was observed that the leucine-supplemented diet could prevent, at least in part, the carcass weight loss and lean carcass mass decrease in the LW group (Table 1). In addition, Ventrucci et al. (9) reported a significant increase in lean body mass in pregnant tumor-bearing animals fed a leucine-supplemented diet compared to the other pregnant tumor-bearing groups. In a previous publication (14), tumor growth promoted some alterations in pregnant rats that could be attenuated by feeding a leucine-supplemented diet. In addition, the intestinal absorption changes demonstrated in the leucine-supplemented groups could prevent hypoglycemia and induced high leucine and methionine absorption mainly in pregnant rats, which 
may increase the availability of amino acids for cells, possibly for host utilization (14).

Many studies have demonstrated that there is a significant increase in proteolysis in cancer patients, twice as large as that observed in malnourished patients (1). This wasting of lean body mass could reveal an incapacity to conserve body protein. The present study showed that the decrease in lean carcass mass was associated with skeletal muscle myosin protein loss in tumorbearing groups. Indeed, these results show that the higher the carcass wasting, the greater the degree of loss in myosin protein (Figure 1). Studies on cancer patients have demonstrated that skeletal muscle was the tissue most severely affected in terms of wasting, while visceral life-supporting tissue was, to a considerable extent, spared (11). It has been demonstrated that in vivo leucine oxidation to $\mathrm{CO}_{2}$ is enhanced in tumor-bearing animals $(3,15)$ and is associated with an increase in amino acid turnover. Argiles et al. (16) suggested that the rate of muscle proteolysis in catabolic states is modulated by factors or compounds by means of a negative feedback loop.

The effects of BCAA on host metabolism have been analyzed in order to clarify the mechanisms involved in altering protein turnover during catabolic states (such as starvation, chronic infection or tumor growth). The plasma concentration of ketone bodies could modulate the extrahepatic oxidation of BCAA, and a decrease in their levels during cancer could result in increased oxidation. The carbon skeletons arising from transamination of BCAA provide a major source of metabolic fuel for skeletal muscle (16). Alternatively, uncontrolled BCAA oxidation may be the result of hypoinsulinemia or peripheral insulin resistance (17). The trigger for the increased leucine oxidation remains unknown. Interestingly, diets containing different proportions of BCAA have shown important beneficial effects on the metabolic changes associated with muscle protein wasting (6). The use of BCAA-enriched total parenteral nutrition in patients with intra-abdominal adenocarcinomas showed an increase in whole body protein synthesis or improved leucine kinetics, fractional albumin synthesis rates, and leucine balance, indicating a favorable influence on protein metabolism (18). Studies have shown that BCAA have a clear inhibitory action on proteolysis in skeletal muscle (19). Yoshizawa et al. (5) showed that refeeding a complete diet to starved rats stimulated protein synthesis in skeletal muscle and liver, demonstrating that the translation initiation in both skeletal muscle and liver in response to refeeding was not associated with any detectable change in the activity or the phosphorylation state of eIF2B in the protein synthesis process. Anthony et al. (20) studied protein synthesis in response to leucine in rats in the post-absorptive state after administration of leucine (1.35 g L-leucine $/ \mathrm{kg}$ ) or saline (control) and the contribution of insulin to this process. Knowing that BCAA are essential nutrients and comprise up to $40 \%$ of the minimal daily requirements of indispensable amino acids (19), this study demonstrates that a leucine-supplemented diet may improve body composition in tumor-bearing rats, especially reducing the carcass weight loss, preserving lean carcass mass and skeletal muscle myosin content (Table 1 and Figure 1).

Further studies are underway in our laboratory to determine if and how leucine supplementation could counteract host carcass wasting during cancer cachexia. The rapid neoplastic growth induced detrimental changes in the host due to carcass wasting. These effects were more severe in the W group than in the LW group. The attenuation of host tissue wastage observed in the tumorbearing leucine-supplemented rats suggests that this amino acid may act, directly and indirectly, on mechanisms leading to stimulation of synthesis and/or inhibition of the oxidation process in host cells. 


\section{Acknowledgments}

The authors are grateful to Dr. Juvenal Marcondes Neto for computing assistance and to Dr. Maria Alice Rostom de Mello for suggestions. Ajinomoto Interamericana Ind. \& Com. Ltda., Corn Products Brazil Ingredients and Roche Industria \& Química S.A. kindly donated the diet ingredients.

\section{References}

1. Tisdale MJ (2002). Cachexia in cancer patients. Nature Reviews. Cancer, 2: 862-871.

2. Rivera S, Azcon-Bieto J, Lopez-Soriano FJ, Miralpeix M \& Argiles JM (1988). Amino acid metabolism in tumour-bearing mice. Biochemical Journal, 249: 443-449.

3. Argiles JM \& Lopez-Soriano FJ (1990). The oxidation of leucine in tumour-bearing rats. Biochemical Journal, 268: 241-244.

4. Vary TC, Jefferson LS \& Kimball SR (1999). Amino acid-induced stimulation of translation initiation in rat skeletal muscle. American Journal of Physiology, 277 (6 Part 1): E1077-E1086.

5. Yoshizawa F, Kimball SR, Vary TC \& Jefferson LS (1998). Effect of dietary protein on translation initiation in rat skeletal muscle and liver. American Journal of Physiology, 275 (5 Part 1): E814-E820.

6. Louard RJ, Barrett EJ \& Gelfand RA (1995). Overnight branchedchain amino acid infusion causes sustained suppression of muscle proteolysis. Metabolism, 44: 424-429.

7. Reeves PG, Nielsen FH \& Fahey Jr GC (1993). AIN-93 purified diets for laboratory rodents: final report of the American Institute of Nutrition ad hoc writing committee on the reformulation of the AIN76A rodent diet. Journal of Nutrition, 123: 1939-1951.

8. Gomes-Marcondes MCC, Cury L \& Curi R (1998). Consequences of Walker 256 tumor growth for the placental/fetal development in rats. Cancer Research, Therapy and Control, 5: 277-283.

9. Ventrucci G, Mello MA \& Gomes-Marcondes MC (2001). Effect of a leucine-supplemented diet on body composition changes in pregnant rats bearing Walker 256 tumor. Brazilian Journal of Medical and Biological Research, 34: 333-338.

10. Gad SC \& Weil CS (1994). Statistics for toxicologists. In: Gad SC \& Weil CS (Editors), Principles and Methods of Toxicology. 3rd edn. Wallace Hayes, Raven Press, Ltd., New York, 221-274.

11. Cohn SH, Gartenhaus W, Sawitsky A, Rai K, Zanzi I, Vaswani A, Ellis KJ, Yasumura S, Cortes E \& Vartsky D (1981). Compartmental body composition of cancer patients by measurement of total body nitro- gen, potassium, and water. Metabolism, 30: 222-229.

12. Gonçalves EL, Waitzberg DL, Bevilacqua RG \& Bevilacqua LR (1990). Body composition in various nutritional conditions. Experimental study. Revista Paulista de Medicina, 108: 125-133.

13. Metzger S, Hassin T, Barash V, Pappo O \& Chajek-Shaul T (2001). Reduced body fat and increased hepatic lipid synthesis in mice bearing interleukin-6-secreting tumor. American Journal of Physiology, 281: E957-E965

14. Ventrucci G, de Mello MA \& Gomes-Marcondes MC (2002). Effects of leucine supplemented diet on intestinal absorption in tumorbearing pregnant rats. BioMedical Central Cancer, 2: 7. [http:// www.biomedcentral.com/1471-2407/2/7]

15. Costelli P, Llovera M, Garcia-Martinez C, Carbo N, Lopez-Soriano FJ \& Argiles JM (1995). Enhanced leucine oxidation in rats bearing an ascites hepatoma (Yoshida $\mathrm{AH}-130)$ and its reversal by clenbuterol. Cancer Letters, 91: 73-78.

16. Argiles JM, Costelli P, Carbo N \& Lopez-Soriano FJ (1996). Branchedchain amino acid catabolism and cancer cachexia. Oncology Reports, 3: 687-690.

17. Tessitore L, Costelli P \& Baccino FM (1993). Humoral mediation for cachexia in tumor-bearing rats. British Journal of Cancer, 67: 15-23.

18. Hunter DC, Weintraub M, Blackburn GL \& Bistrian BR (1989). Branched chain amino acids as the protein component of parenteral nutrition in cancer cachexia. British Journal of Surgery, 76: 149-153.

19. Busquets S, Alvarez B, Llovera M, Agell N, Lopez-Soriano FJ \& Argiles JM (2000). Branched-chain amino acids inhibit proteolysis in rat skeletal muscle: mechanisms involved. Journal of Cellular Physiology, 184: 380-384.

20. Anthony JC, Lang CH, Crozier SJ, Anthony TG, MacLean DA, Kimball SR \& Jefferson LS (2002). Contribution of insulin to the translational control of protein synthesis in skeletal muscle by leucine. American Journal of Physiology, 282: E1092-E1101. 